\title{
Experimental Investigation of the Effect of Working Parameters on Wire Offset in Wire Electrical Discharge Machining of Hadfield Manganese Steel
}

\author{
Ashok Kumar Srivastava ${ }^{1 *}$, Surjya Kanta Pal ${ }^{2}$, Probir Saha ${ }^{3}$, Karabi Das ${ }^{4}$ \\ ${ }^{1}$ Centre of Excellence in Materials Science \& Engineering, Department of Metallurgical Engineering, OP Jindal Institute of Technol- \\ ogy Raigarh, Chhattisgarh, India; ${ }^{2}$ Department of Mechanical Engineering, IIT Kharagpur, West Bengal, India; ${ }^{3}$ Department of Me- \\ chanical Engineering, IIT Patna, Bihar; ${ }^{4}$ Department of Metallurgical and Materials Engineering, IIT Kharagpur, West Bengal, India. \\ Email: *ashok.iitkgp@yahoo.co.uk
}

Received July 25 ${ }^{\text {th }}, 2013$; revised August $20^{\text {th }}, 2013$; accepted September $15^{\text {th }}, 2013$

Copyright (C) 2013 Ashok Kumar Srivastava et al. This is an open access article distributed under the Creative Commons Attribution License, which permits unrestricted use, distribution, and reproduction in any medium, provided the original work is properly cited.

\begin{abstract}
In this study, a series of tests have been conducted in order to investigate the machinability evaluation of austenitic Hadfield manganese steel in the Wire Electrical Discharge Machine (WEDM). Experimental investigations have been carried out to relate the effect of input machining parameters such as pulse on-time $\left(T_{\text {on }}\right)$, pulse off-time $\left(T_{\text {off }}\right)$, wire feed $\left(\mathrm{W}_{\mathrm{F}}\right)$, and average gap voltage $(\mathrm{V})$ on the wire offset in WEDM. No analytical approach gives the exact amount of offset required in WEDM and hence experimental study has been undertaken. In this paper, a mathematical model has been developed to model the machinability evaluation through the response surface methodology (RSM) capable of predicting the response parameter as a function of $T_{\text {on }}, T_{\text {off }}, \mathrm{W}_{\mathrm{F}}$ and $\mathrm{V}$. The samples are tested and their average prediction error has been calculated taking the average of all the individual prediction errors. The result shows that this mathematical model reflects the independent, quadratic and interactive effects of the various machining parameters on cutting speed in WEDM process.
\end{abstract}

Keywords: Hadfield Manganese Steel; WEDM; Pulse Time; Wire Offset; Average Gap Voltage; Response Surface Methodology

\section{Introduction}

Hadfield manganese steel, with a composition of $\mathrm{Fe}-$ $1.2 \% \mathrm{C}-13 \% \mathrm{Mn}$, is a remarkable engineering alloy in that it is soft and ductile in the fully austenitic phase form. However, when deformed, it rapidly work-hardens, even though it may suffer considerable wear from non-impact abrasive conditions, and impacting or gouging deformation quickly causes it to work-harden [1]. This property makes the steel very useful in applications where heavy impact and abrasion are involved, such as within a jaw crusher, impact hammer, rail-road crossing (frog), etc. [2].

Wire Electrical Discharge Machining (WEDM) is an electro thermal production process in which thin singlestrand metal wire in conjunction with de-ionized water (used to conduct electricity) cuts through metal by the use of heat from electrical sparks [3]. WEDM is a widely accepted and non-traditional machining process is used

"Corresponding author. to manufacture components with intricate shapes and profiles [4]. WEDM is found to be an extremely potential electrothermal process [5,6], since it can be used in machining of high strength and temperature resistive (HSTR), and it is hard and difficult to machine conductive engineering materials with intricate shapes. WEDM is a widespread technique used in industry for high-precision machining of all types of conductive materials such as metals, metallic alloys, graphite, or even some ceramic materials, of any hardness $[4,7,8]$. Wire-EDM is capable of producing a fine, precise, corrosion-resistance and wearresistance surface [9]. WEDM uses a series of voltage pulses, usually in rectangular form, of magnitudes of up to $400 \mathrm{~V}$ and those of the frequencies of the order of 5 $\mathrm{kHz}-200 \mathrm{kHz}$, applied between the electrodes, which are separated by a small gap, typically $10-100$ microns [10]. A thin $0.05-0.30 \mathrm{~mm}$ diameter wire performs as the electrode in WEDM and the gap between the wire and work piece is flooded with deionized water, which acts as the dielectric. Material is eroded ahead of the 
traveling wire from the work piece by a series of discrete sparks [11].

Hadfield manganese steels are in general difficult to machine due to their hardness and abrasive nature of reinforced particles. The formation of ferric oxide $\left(\mathrm{Fe}_{2} \mathrm{O}_{3}\right)$ makes the WEDM process very much unstable. The generation of abnormal sparks such as arcing, short circuit, etc. leads to such instability. It is, thus, complicated to model the process by an analytical approach based on the physics of this process. Therefore, selection of optimal parametric combination for obtaining better cutting performance is a challenging task in WEDM while machining the aforesaid material. And hence, any attempt to model and optimize the process would be useful [12].

The objective of the present work is to study the effect of different WEDM process parameters on the wire offset during machining Hadfield manganese steel. An offset is needed to make the part of the exact size while using the power settings provided for the particular material. Dimensional deviation or wire offset arises due to the force generated by electro-discharge during cutting making electrode wire bend and deviate a tiny distance [13]. No analytical approach gives the exact amount of offset required and hence experimental study is undertaken. An attempt is made to develop a model using the Response Surface Methodology (RSM), correlating input and output parameters of the process.

\section{Design of Experiments}

During machining, it is required to relate the input variables such as pulse on-time $\left(\mathrm{T}_{\mathrm{on}}\right)$, pulse off-time $\left(\mathrm{T}_{\mathrm{off}}\right)$, wire feed $\left(\mathrm{W}_{\mathrm{F}}\right)$, and average gap voltage $(\mathrm{V})$ to the wire offset of the process by a mathematical model. RSM is a collection of mathematical and statistical procedures that are useful for the modeling and the analysis of problems in which response of demand is affected by several variables and the objective is to optimize this response [14, 15]. The essential of RSM is for replacing a complex model by an approximate one based on results calculated at various points in the design space. RSM is especially fit for long time computation consuming problems. Generally, RSM that employs low-order polynomial functions (2-order is implemented often) can efficiently model loworder problems, and corresponding computation of a RS model is fast and cheap. In addition, RSM facilitates the understanding of engineering problems by comparing parameter coefficients and also in the elimination of unimportant design variables. Low-order polynomial response surfaces are not good for highly nonlinear problems, such as sheet metal optimization. Thus, design of experiment (DOE) has become the determining factor for accuracy and efficiency of RS. There were several improvements of DOE presented in the literature [16-22].
For the most of RS, the functions for the approximations are polynomials because of simplicity, though the functions are not limited to the polynomials. For the cases of quadratic polynomials, the response surface is described by Equation (1):

$$
Y=\beta_{0}+\sum_{j=1}^{k} \beta_{j} X_{j}+\sum_{j=1}^{k} \beta_{i j} X_{j}^{2}+\sum_{i=1}^{k-1} \sum_{j=i+1}^{k} \beta_{i j} X_{i} X_{j}
$$

where $k$ is the number of design variables. In the case of four variables, the response surface can be expressed by Equation (2):

$$
\begin{aligned}
Y & =\beta_{0}+\beta_{1} X_{1}+\beta_{2} X_{2}+\beta_{3} X_{3}+\beta_{4} X_{4} \\
& +\beta_{11} X_{1}^{2}+\beta_{22} X_{2}^{2}+\beta_{33} X_{3}^{2}+\beta_{44} X_{4}^{2} \\
& +\beta_{12} X_{1} X_{2}+\beta_{13} X_{1} X_{3}+\beta_{14} X_{1} X_{4} \\
& +\beta_{23} X_{2} X_{3}+\beta_{24} X_{2} X_{4}+\beta_{34} X_{3} X_{4}
\end{aligned}
$$

By replacements of $X_{5}=X_{1}^{2}, X_{6}=X_{2}^{2}, X_{7}=X_{3}^{2}$, $X_{8}=X_{4}^{2}, X_{9}=X_{1} X_{2}, X_{10}=X_{1} X_{3}, X_{11}=X_{1} X_{4}, X_{12}=X_{2}$ $X_{3}, X_{13}=X_{2} X_{4}, X_{14}=X_{3} X_{4}, \beta_{11}=\beta_{5}, \beta_{22}=\beta_{6}, \beta_{33}=\beta_{7}$, $\beta_{44}=\beta_{8}, \beta_{12}=\beta_{9}, \beta_{13}=\beta_{10}, \beta_{14}=\beta_{11}, \beta_{23}=\beta_{12}, \beta_{24}=\beta_{13}$, $\beta_{34}=\beta_{14}$, the following Equation (3) becomes a linear regression model as follows:

$$
\begin{aligned}
Y= & \beta_{0}+\beta_{1} X_{1}+\beta_{2} X_{2}+\beta_{3} X_{3}+\beta_{4} X_{4}+\beta_{5} X_{5} \\
& +\beta_{6} X_{6}+\beta_{7} X_{7}+\beta_{8} X_{8}+\beta_{9} X_{9}+\beta_{10} X_{10} \\
& +\beta_{11} X_{11}+\beta_{12} X_{12}+\beta_{13} X_{13}+\beta_{14} X_{14}
\end{aligned}
$$

In the case that total number of experiments is $n$; the response surface can be expressed by the following matrix Equations (4) and (5):

$$
\bar{Y}=\bar{X} \bar{B}+\bar{\varepsilon}
$$

where,
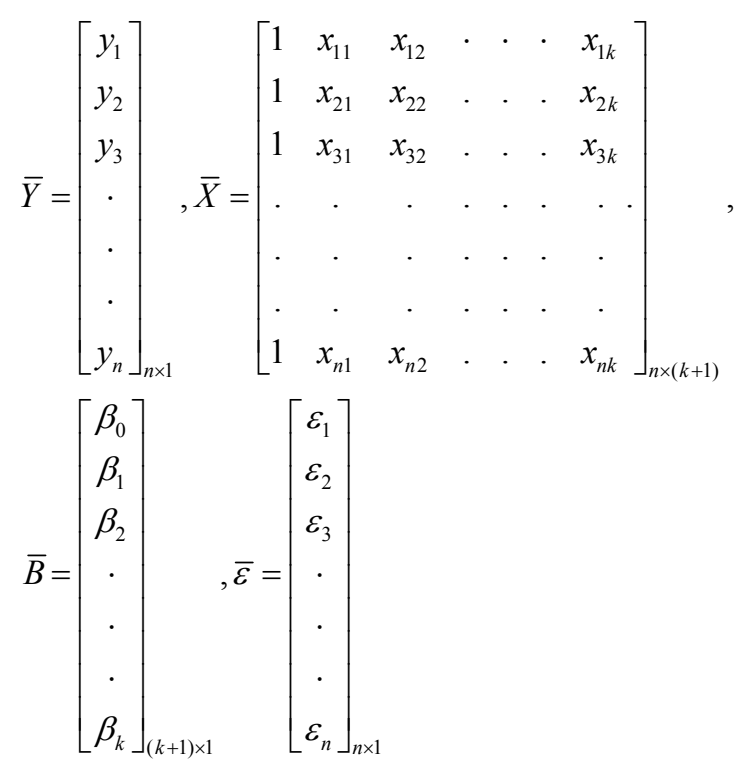

where $\varepsilon$ is an error vector. 


\section{Experiential Procedure}

During this study, a series of experiments were conducted on Electra Maxicut model, CNC wire-EDM machine, manufactured by Electronica M/C Tools Limited, Pune (India). A schematic drawing and a photograph of the experimental system is shown in Figure 1. The voltage and current waveform during machining has also been stored into a computer by using Hall Effect sensors (LA 55-P, LEM) and $100 \mathrm{MHz}$ digital storage oscilloscope (Agilient-54624A model) with a sampling speed of 1 mega samples/sec. In this machine there are total $10 \mathrm{knob}$ positions $(1-10)$ to vary peak current. It has been seen that peak current increases with knob position.

The constant parameters were: Wire material-Brass, Hadfield manganese steel specimens of hardness 45 - 46 HRC, Wire diameter-250 $\mu \mathrm{m}$, Wire tension-1000 gf, Dielectric fluid-deionized water, Up flushing rate $-4 \mathrm{lt} / \mathrm{min}$, Down flushing rate $-5 \mathrm{lt} / \mathrm{min}$, Peak current $-2 \mathrm{amp}$, Length of cut $-6 \mathrm{~mm}$, Capacitor $-1 \mu \mathrm{F}$. The coded and actual values of each parameter used in this work are listed in Table 1. From the coded form of parameters, the corresponding actual parameters and results of output parameters are listed in Table 2.

Four input machining parameters such as pulse ontime $\left(\mathrm{T}_{\text {on }}\right)$, pulse off-time $\left(\mathrm{T}_{\text {off }}\right)$, wire feed $\left(\mathrm{W}_{\mathrm{f}}\right)$, average gap voltage $(\mathrm{V})$ have been varied to see their effect on output parameter i.e. wire offset. Hadfield manganese

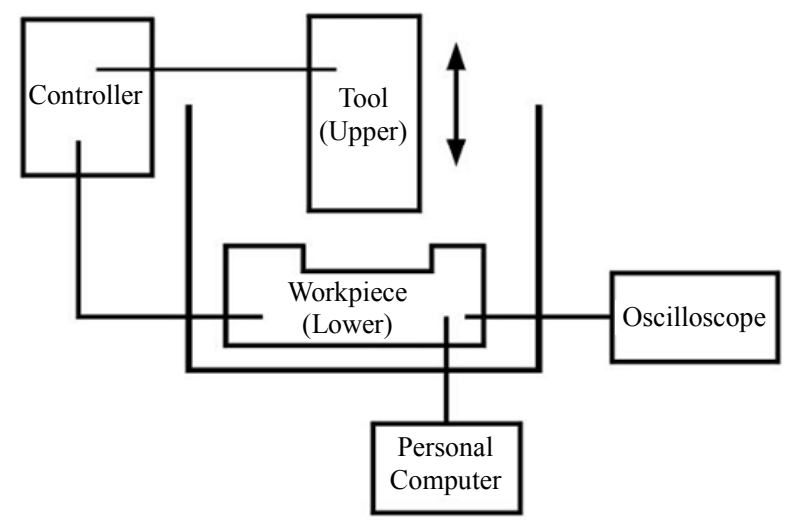

(a) steel samples of $15 \mathrm{~mm} \times 15 \mathrm{~mm} \times 10 \mathrm{~mm}$ were used. An optical microscope (Model: SDM 210, Metal Power Pvt. Ltd., Mumbai) was used to measure the width of the slit of the work piece formed by WEDM. Figure 2 shows the photographs of sample after machining.

\section{Results and Discussions}

\subsection{Regression Analysis}

The analysis of variance (ANOVA) was developed by the researchers to test hypotheses about the situations where there are two or more means being compared. Though initially dealing with agricultural data [23], this methodology has been applied to a vast array of other fields for data analysis. It is conceptually the same as regression. It allows researcher to evaluate all of the mean differences in a single hypothesis test. An F-test is any statistical test in which the test statistic has an F-distribution under the null hypothesis. It is most often used when comparing statistical models that have been fitted to a dataset, in order to identify the model that best fits the population from which the data were sampled. Exact F-tests mainly arise when the models have been fitted to the data using least squares. The tests in an ANOVA are based on the F-ratio: the variation due to an experimental treatment or effect divided by the variation due to experimental error.

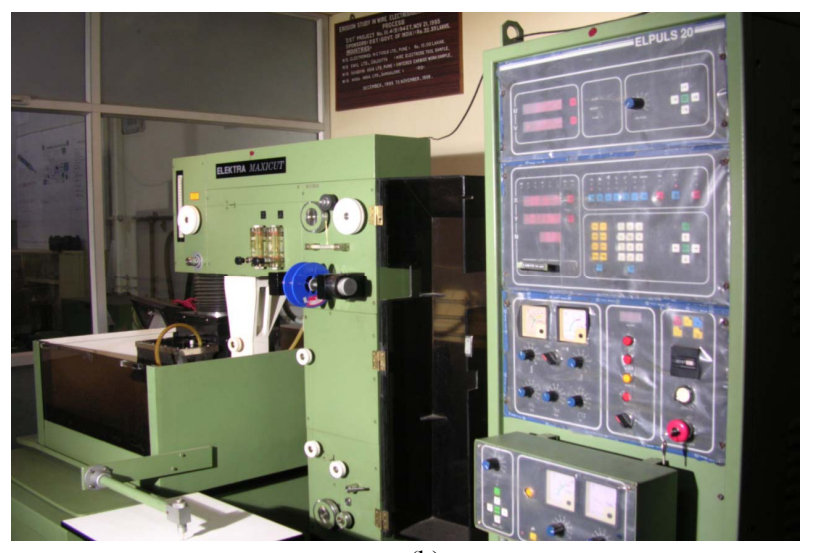

(b)

Figure 1. Showing: (a) a schematic drawing and (b) a photograph of the experimental system.

Table 1. Coding of process parameters.

\begin{tabular}{ccccc}
\hline Level & Pulse on time " $\mathrm{T}_{\text {on }}$ " $(\mu \mathrm{s})$ & Pulse off time " $\mathrm{T}_{\text {off }}$ " $(\mu \mathrm{s})$ & Wire feed " $\mathrm{W}_{\mathrm{F}}$ " $(\mathrm{m} / \mathrm{min})$ & Average gap "V" (volts) \\
\hline-2 & 6 & 5 & 2 & 50 \\
-1 & 8 & 15 & 3 & 56 \\
0 & 10 & 25 & 4 & 62 \\
+1 & 12 & 35 & 5 & 68 \\
+2 & 14 & 45 & 6 & 74 \\
\hline
\end{tabular}


Table 2. Design of experiments and results (actual parameters).

\begin{tabular}{|c|c|c|c|c|c|c|c|}
\hline Exp. No & $\mathrm{T}_{\text {on }}(\mu \mathrm{s})$ & $\mathrm{T}_{\text {off }}(\mu \mathrm{s})$ & $\mathrm{W}_{\mathrm{F}}(\mathrm{m} / \mathrm{min})$ & Avg GapVolt (V) & Time (min) & Average Kerf width $(\mu \mathrm{m})$ & Wire offset $(\mathrm{mm}$ \\
\hline 1 & 12 & 35 & 3 & 68 & 5.079 & 325.533 & 0.163 \\
\hline 2 & 10 & 5 & 4 & 62 & 4.269 & 350.75 & 0.175 \\
\hline 3 & 8 & 35 & 3 & 56 & 3.868 & 345.825 & 0.173 \\
\hline 4 & 10 & 25 & 4 & 62 & 4.295 & 366.908 & 0.183 \\
\hline 5 & 10 & 25 & 4 & 50 & 3.293 & 355.241 & 0.178 \\
\hline 6 & 10 & 25 & 4 & 62 & 4.369 & 376.075 & 0.188 \\
\hline 7 & 14 & 25 & 4 & 62 & 4.293 & 374.708 & 0.187 \\
\hline 8 & 12 & 35 & 3 & 56 & 3.652 & 365.65 & 0.183 \\
\hline 9 & 10 & 25 & 4 & 62 & 4.271 & 372.05 & 0.186 \\
\hline 10 & 12 & 15 & 5 & 68 & 5.171 & 373.891 & 0.187 \\
\hline 11 & 10 & 25 & 6 & 62 & 4.642 & 363.366 & 0.182 \\
\hline 12 & 8 & 15 & 5 & 68 & 5.298 & 364.408 & 0.182 \\
\hline 13 & 10 & 25 & 4 & 74 & 7.013 & 388.858 & 0.194 \\
\hline 14 & 8 & 35 & 5 & 68 & 5.894 & 381.633 & 0.191 \\
\hline 15 & 10 & 25 & 2 & 62 & 4.220 & 367.708 & 0.184 \\
\hline 16 & 10 & 25 & 4 & 62 & 4.243 & 369.8 & 0.185 \\
\hline 17 & 12 & 15 & 5 & 56 & 3.633 & 360.7 & 0.180 \\
\hline 18 & 6 & 25 & 4 & 62 & 4.539 & 378.533 & 0.189 \\
\hline 19 & 12 & 15 & 3 & 68 & 5.224 & 389.116 & 0.195 \\
\hline 20 & 10 & 25 & 4 & 62 & 4.469 & 379.333 & 0.190 \\
\hline 21 & 12 & 15 & 3 & 56 & 3.492 & 371.875 & 0.186 \\
\hline 22 & 8 & 15 & 3 & 68 & 5.302 & 395.933 & 0.198 \\
\hline 23 & 8 & 35 & 3 & 68 & 5.759 & 388.441 & 0.194 \\
\hline 24 & 10 & 25 & 4 & 62 & 4.365 & 377.858 & 0.189 \\
\hline 25 & 10 & 45 & 4 & 62 & 4.636 & 360.975 & 0.180 \\
\hline 26 & 8 & 15 & 3 & 56 & 3.702 & 342.425 & 0.171 \\
\hline 27 & 8 & 35 & 5 & 56 & 4.027 & 364.758 & 0.182 \\
\hline 28 & 10 & 25 & 4 & 62 & 4.391 & 372.616 & 0.186 \\
\hline 29 & 12 & 35 & 5 & 68 & 5.612 & 369.075 & 0.185 \\
\hline 30 & 12 & 35 & 5 & 56 & 3.781 & 363.183 & 0.182 \\
\hline 31 & 8 & 15 & 5 & 56 & 3.931 & 358.041 & 0.179 \\
\hline
\end{tabular}

ANOVA and the F-ratio test have been performed to justify the goodness of fit of the developed mathematical models. The calculated values of F-ratio for the lack of fit are found to be lesser than the standard value of the F-ratio. The second order regression models are adequate at $95 \%$ confidence level. Hence, the developed mathe- matical models, which correlate the various machining parameters with wire offset, can adequately be represented through the Response Surface Methodology.

Using software "MINITAB", the values of the regression coefficients of Equation (2) is calculated for cutting speed and presented by Equation (6): 

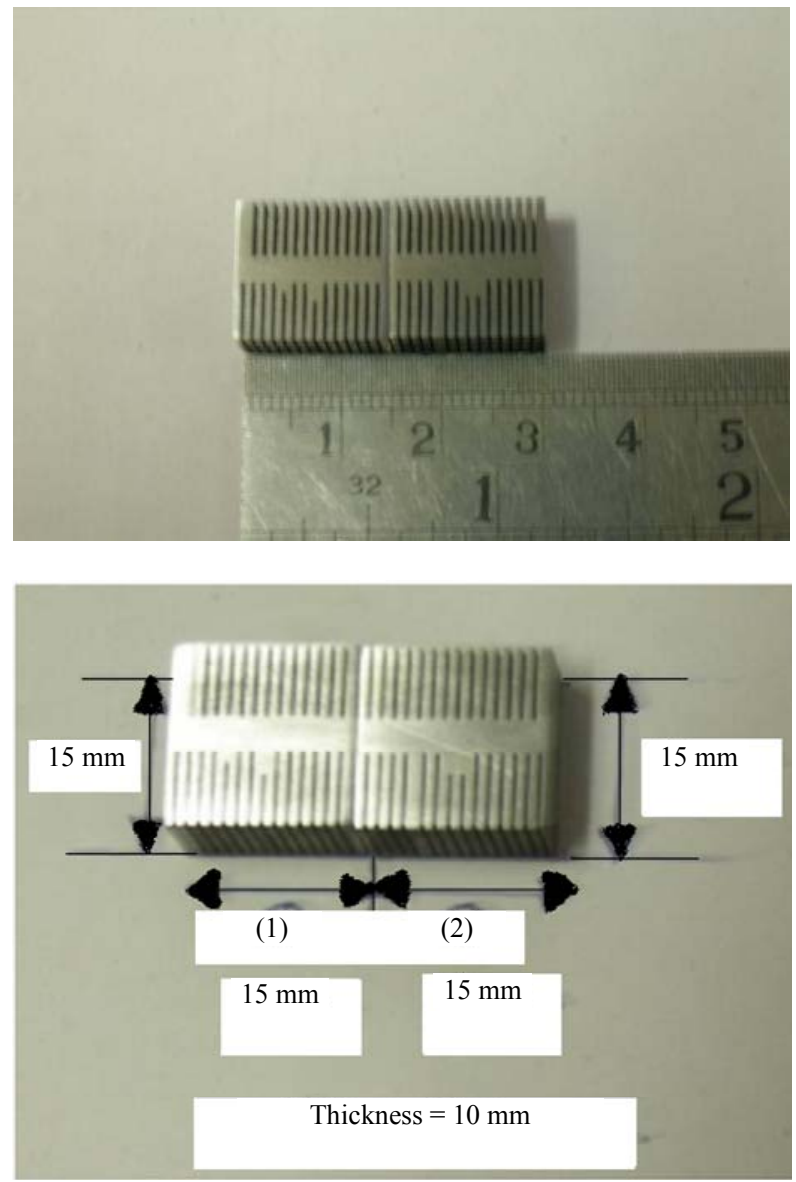

Figure 2. Photographs of Hadfield manganese steel after machining with WEDM.

$$
\begin{aligned}
& \text { Cutting Speed }=2.62558+0.07573 X_{1} \\
& +0.00044 X_{2}-0.13193 X_{3}-0.00294 X_{4} \\
& -0.00007 X_{2}^{2}-0.00028 X_{4}^{2} \\
& -0.00097 X_{1} X_{4}+0.00097 X_{3} X_{4}
\end{aligned}
$$

The computed values of the response parameters from the above regressions were plotted to study the influence of the process parameters on the output variables cutting speed and wire offset. Figure 3 shows the graph of actual and predicted wire offset.

\subsection{Effect of Working Parameters on Wire Offset}

\subsubsection{Effect of Pulse on-Time ( $\left.T_{\text {on }}\right)$ on Wire Offset}

Figure 4 shows the effect of pulse on-time on the wire offset. It has been observed that at lower gap voltage the wire offset increases with the increase in pulse on time. It is because that at higher $T_{\text {on }}$, the discharge energy increases resulting in larger overcut which in turn increases the value of wire offset. At higher gap voltage the situation is completely reversed.

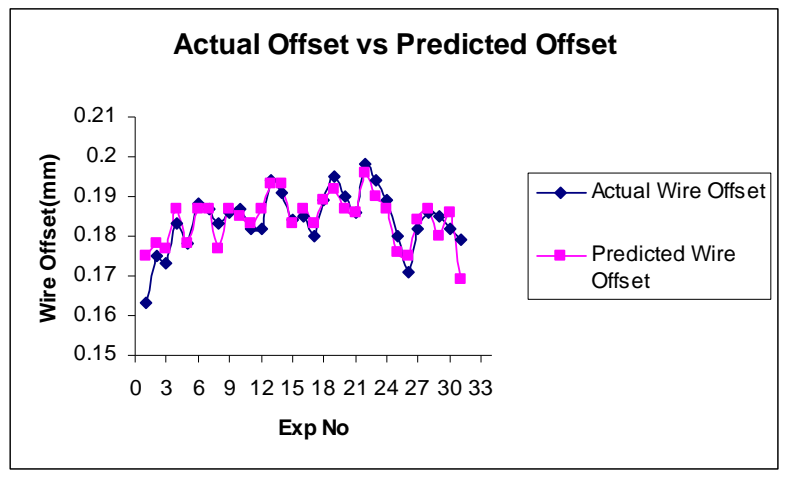

Figure 3. Graph of actual and predicted wire offset.

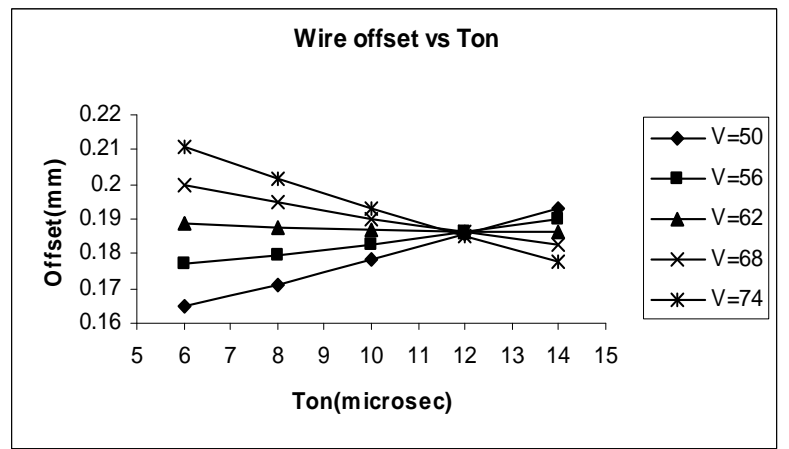

Figure 4. Effect of pulse on time $\left(\mathrm{T}_{\mathrm{on}}\right)$ on wire offset at different gap voltages $(\mathrm{V})$. (At $\mathrm{W}_{\mathrm{F}}=4 \mathrm{~m} / \mathrm{min}$ and pulse off time $\left.T_{\text {off }}=25 \mu \mathrm{s}\right)$.

\subsubsection{Effect of Pulse Off-Time ( $\left.T_{\text {off }}\right)$ on Wire Offset} The effect of pulse off-time on wire offset has been shown in Figure 5. For a particular gap voltage, wire offset increases initially and then starts decreasing. With too short pulse off time, there is not enough time to clear the disintegrated particles from the gap between the electrode and the work-piece. There is also not enough time for de-ionization of the dielectric fluid. As a result arcing occurs and wire offset increases initially. On the other hand, at long pulse off time this phenomenon does not occur resulting in stable machining and hence reduces wire offset.

\subsubsection{Effect of Wire Feed (WF) on Wire Offset}

The effect of wire feed on wire offset is shown in Figure 6. It shows that an increase in wire feed increases wire offset initially, then starts to decrease for a particular gap voltage. This is due to the fact that the contact time between the wire and electrode decreases. As a result, less number of sparks are obtained and hence less kerf width. So wire offset tends to decrease.

\subsubsection{Effect of Average Gap Voltage (V) on Wire Offset}

The effect of average gap voltage on the wire offset has 


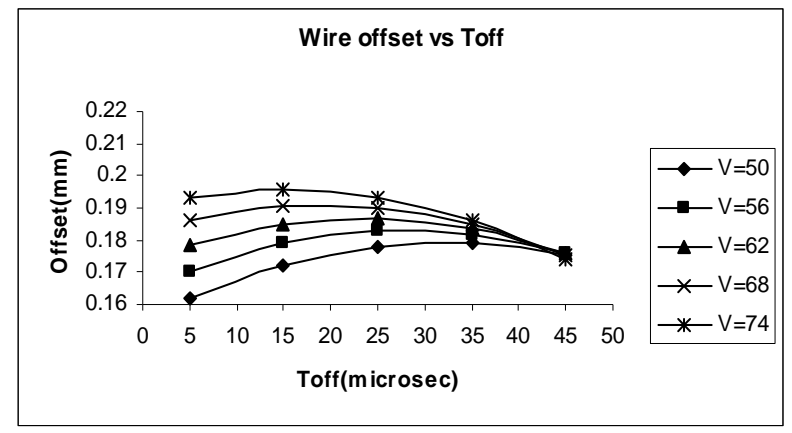

Figure 5. Effect of pulse off time $\left(\mathrm{T}_{\text {off }}\right)$ on wire offset at different gap voltages $(\mathrm{V})$. (At $\mathrm{W}_{\mathrm{F}}=4 \mathrm{~m} / \mathrm{min}$ and pulse on time $\left.\mathbf{T}_{\mathrm{on}}=\mathbf{1 0} \boldsymbol{\mu s}\right)$.

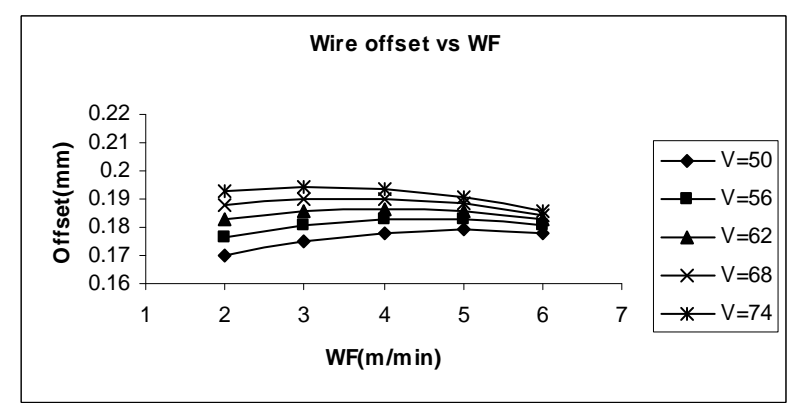

Figure 6. Effect of wire feed $\left(W_{F}\right)$ on wire offset at different gap voltages $(\mathrm{V})$. (At pulse off time $T_{\text {off }}=25 \mu$ s and pulse on time $\left.T_{\text {on }}=10 \mu \mathrm{s}\right)$.

been shown in Figure 7. It has been observed that at lower pulse on time the wire offset increases with increase in gap voltage. This is due to the fact that at higher gap voltage the gap between the wire and work piece increases resulting unstable machining which in turn increases the kerf width. But at higher pulse on time the situation is completely reversed.

\subsection{The Surface Plots of Wire Offset vs. Input Parameters}

Figure 8 shows interaction effect of $T_{\text {on }}$ and $T_{\text {off }}$ on wire offset. Here as we increase $\mathrm{T}_{\text {on }}$, wire offset decreases initially and then tends to decrease at higher pulse off time. At lower pulse on time, wire offset increases a huge amount then decreases a little, as pulse off time is increased. For higher pulse on time, wire offset increases a little then decreases by huge amount as pulse off time is increased. Figure 9 shows interaction effect of $\mathrm{T}_{\text {on }}$ and Average volt on wire offset. As $\mathrm{T}_{\text {on }}$ increases, wire offset increases. Consequently on increasing average gap voltage, wire offset increases initially and then it decreases. Figure 10 shows interaction effect of $T_{\text {on }}$ and $\mathrm{W}_{\mathrm{f}}$ on wire offset. Here at lower wire feed, if $\mathrm{T}_{\text {on }}$ is increased, wire offset decreases. But as we go to higher wire feeds, if $\mathrm{T}_{\text {on }}$ is increased, wire offset decreases initially and then it

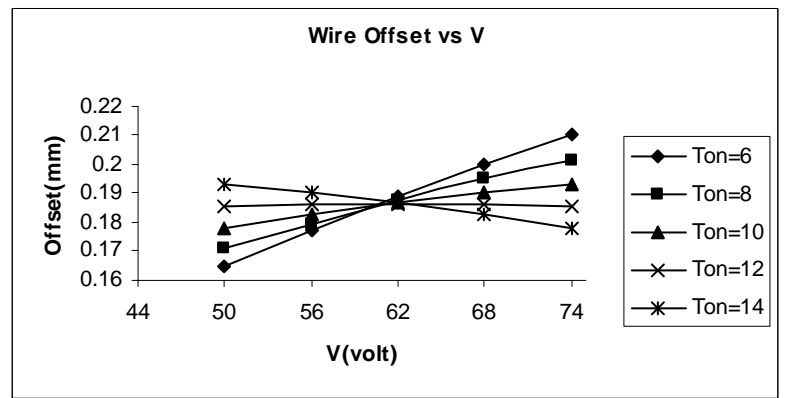

Figure 7. Effect of average gap voltage $(\mathrm{V})$ on wire offset at different pulse on time $\left(T_{\text {on }}\right)$. (At pulse off time $T_{\text {off }}=25 \mu \mathrm{s}$ and wire feed $\left.W_{F}=4 \mathrm{~m} / \mathrm{min}\right)$.

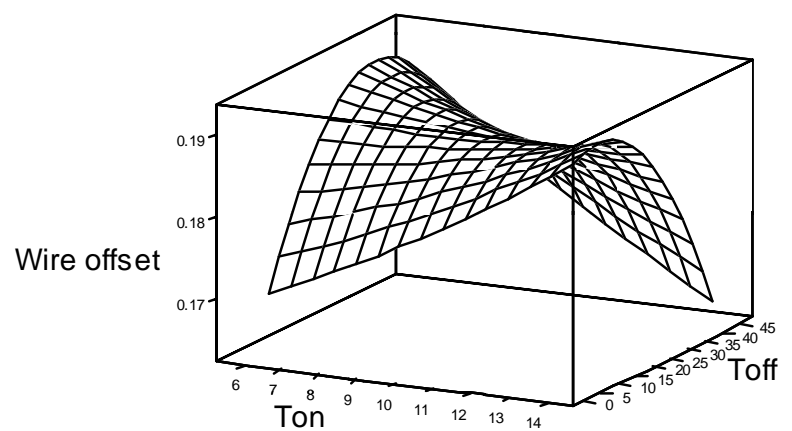

Figure 8. Interaction effect of $T_{\text {on }}$ and $T_{\text {off }}$ on wire offset. (Hold values- $W_{F}$ : 4.0; Avg. volt: 62.0).

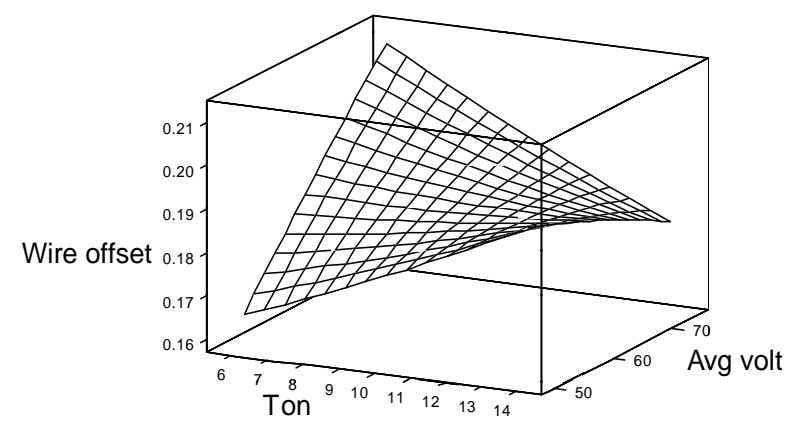

Figure 9. Interaction effect of $T_{\text {on }}$ and Avg. volt on wire offset. (Hold values- $T_{\text {off }}: 25.0 ; W_{F}: 4.0$ ).

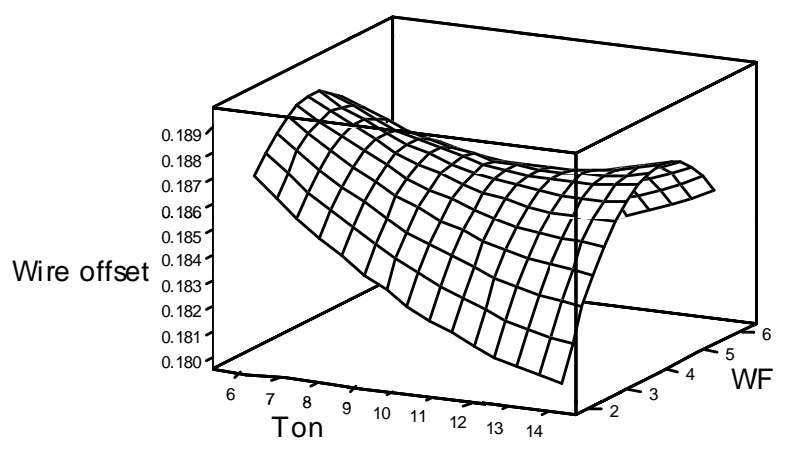

Figure 10. Interaction effect of $T_{\text {on }}$ and $W_{F}$ on wire offset. (Hold values- $T_{\text {off: }}$ 25.0; Avg. volt: 62.0). 


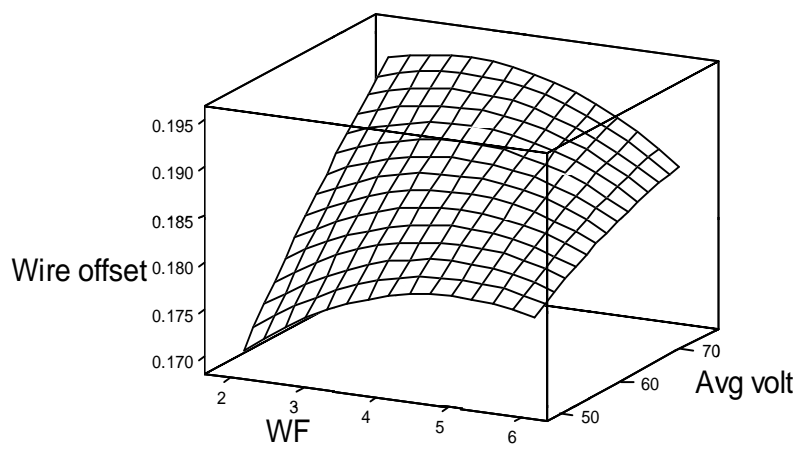

Figure 11. Interaction effect of $W_{F}$ and Avg. volt on wire offset. (Hold values- $\left.T_{\text {on }}: 10.0 ; T_{\text {off }}: 25.0\right)$.

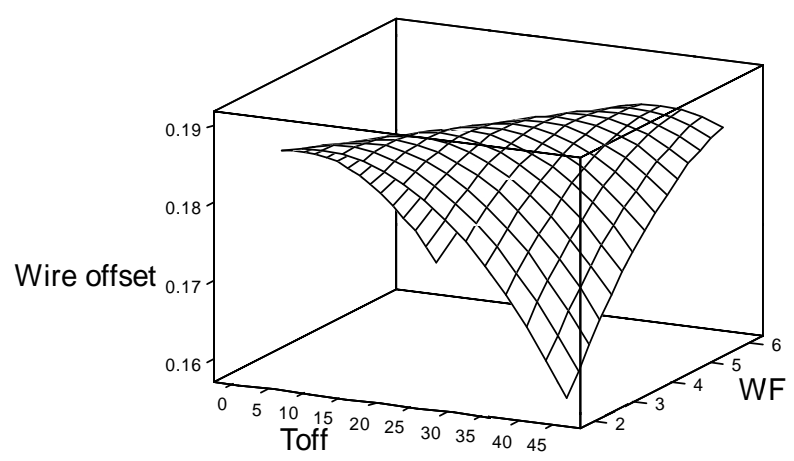

Figure 12. Interaction effect of $T_{\text {off }}$ and $W_{F}$ on wire offset. (Hold values- $T_{\text {on }}$ : 10.0; Avg. volt: 62.0).

starts to increase.

Figure 11 shows interaction effect of $\mathrm{W}_{\mathrm{F}}$ and Avg. $\mathrm{V}$ on wire offset. In this case, as wire feed is increased, wire offset increases initially a little and then it decreases. Also with the increase of average gap voltage, wire offset increases. Figure 12 shows interaction effect of $\mathrm{T}_{\text {off }}$ and $\mathrm{W}_{\mathrm{F}}$ on wire offset. In this case, at lower wire feed, if $\mathrm{T}_{\text {off }}$ is increased, wire offset increases a small amount then it goes on decreasing. But at higher wire feeds, wire offset increases a huge amount then it decreases marginally.

\section{Conclusion}

Response Surface Methodology (RSM) has been used to model the process. The model is capable of predicting the response parameters as the function of pulse on-time, pulse off-time, wire feed and average gap voltage. Test results demonstrate that the model is suitable for predicting the response parameter very well. In the experimental part of this work, the effect of pulse on-time, pulse offtime, wire feed and average gap voltage on wire offset has been investigated. It has been found that an increase in pulse on-time provides higher wire offset; an increase in pulse off-time provides lower wire offset; wire feed has minor effect giving lower wire offset and lastly an increase in average gap voltage causes wire offset to in- crease.

\section{REFERENCES}

[1] B. Lva, M. Zhang, F. C. Zhang, C. L. Zheng, X. Y. Feng, L. H. Qian and X. B. Qin, "Micro-Mechanism of Rolling Contact Fatigue in Hadfield Steel Crossing," International Journal of Fatigue, Vol. 44, 2012, pp. 273-278. http://dx.doi.org/10.1016/j.ijfatigue.2012.04.010

[2] J. Mendez, M. Ghoreshy, W. B. F. Mackay, T. J. N. Smith and R. W. Smith, "Weldability of Austenitic Manganese Steel," Journal of Materials Processing Technology, Vol. 153-154, 2004, pp. 596-602.

http://dx.doi.org/10.1016/j.jmatprotec.2004.04.033

[3] G. Amitesh and K. Jatinder, "An Investigation into the Machining Characteristics of Nimonic 80a Using CNC Wire-EDM," International Journal of Advanced Engineering Technology, Vol. III, No. I, 2012, pp. 170-174.

[4] K. H. Ho, S. T. Newman, S. Rahimifard and R. D. Allen, "State of the Art in Wire Electrical Discharge Machining (WEDM)," International Journal of Machine Tools \& Manufacture, Vol. 44, No. 12-13, 2004, pp. 1247-1259. http://dx.doi.org/10.1016/j.ijmachtools.2004.04.017

[5] M. S. Phadke, "Quality Engineering Using Robust Design,” Prentic Hall, Englewood Cliffs, 1989.

[6] J. Matsuda, S. Tomishige, K. Tanaka and Ii. Yano, "Evaluation of Performance of WEDM by Parameter Design," Proceedings of the International Symposium for ElectraMachining, (ISFM-9), Nagoya, 1989, pp. 68-71.

[7] L. Gatto, "Cutting Mechanisms and Surface Features of WEDM Metal Matrix Composite," Journal of Material Processing Technology, Vol. 65, No. 1-3, 1997, pp. 209214. http://dx.doi.org/10.1016/S0924-0136(96)02264-9

[8] C. J. Luis Puertas, "A Study on the Machining Parameters Optimization of Electrical Discharge Machining," Journal of Materials Processing Technology, Vol. 143-144, 2003, pp. 521-526.

http://dx.doi.org/10.1016/S0924-0136(03)00392-3

[9] Y. Y. S. Liaoa, J. T. Huang and Y. H. Chena, "A Study to Achieve a Fine Surface Finish in Wire-EDM," Journal of Materials Processing Technology, Vol. 149, No. 1-3, 2004, pp. 165-171.

http://dx.doi.org/10.1016/j.jmatprotec.2003.10.034

[10] A. Behrens and M. P. Witzak, "New Arc Detection Technology for Highly Efficient Electro-Discharge Machining," Draft Paper Dies and Molds, 1997.

[11] G. F. Benedict, "Non-Traditional Manufacturing Processes," Marcel Dekker, New York, 1987.

[12] P. Saha, D. Tarafdar, S. K. Pal, P. Saha, A. K. Srivastava and K. Das, "Multi-Objective Optimization in Wire-Electro-Discharge Machining of TiC Reinforced Composite through Neuro-Genetic Technique," Applied Soft Computing, Vol. 13, No. 4, 2013, pp. 2065-2074. http://dx.doi.org/10.1016/j.asoc.2012.11.008

[13] X. J. Li and Y. H. Hu, "Machining Precision Research for Two WEDM Processes," Proceedings of the 2nd International Conference on Computer Science and Electronics 
Engineering (ICCSEE 2013), pp. 2169-2172.

[14] R. H. Myers and D. C. Montgomery, "Response Surface Methodology: Process and Product Optimization Using Designed Experiments," John Wiley \& Sons, New York, 1995.

[15] D. C. Montgomery, "Design and Analysis of Experiments," John Wiley \& Sons, New York, 2001.

[16] G. E. P. Box and N. R. Draper, "Evolutionary Operation: A Statistical Method for Process Management," John Wiley \& Sons, New York, 1969.

[17] W. Chen, J. K. Allen, D. P. Schrage and F. Mistree, "Statistical Experimentation Methods for Achieving Affordable Concurrent Systems Design," AIAA Journal, Vol. 35, No. 5,1997 , pp. 893-900. http://dx.doi.org/10.2514/2.7464

[18] B. A. Wujek and J. E. Renaud, "New Adaptive Move-Limit Management Strategy for Approximate Optimization. Part 1," AIAA Journal, Vol. 36, No. 10, 1991, pp. 19111921. http://dx.doi.org/10.2514/2.285

[19] V. Toropov, F. Van Keulen, V. Markine and H. De Doer, "Refinements in the Multi-Point Approximation Method to Reduce the Effects of Noisy Structural Responses," Proceedings of the 6th AIAA/USAF/NASA/ISSMO Sympo- sium on Multidisciplinary Analysis and Optimization, Vol. 2, AIAA, Bellevue, 1996, pp. 941-951.

[20] N. Alexandrov, J. E. Dennis Jr., R. M. Lewis and V. Torczon, "A Trust Region Framework for Managing the Use of Approximation Models in Optimization," Structural Optics, Vol. 15, No. 1, 1998, pp. 16-23. http://dx.doi.org/10.1007/BF01197433

[21] G. G. Wang and T. Simpson, "Fuzzy Clustering-Based Hierarchical Meta Modeling for Design Space Reduction and Optimization," Engineering Optics, Vol. 36, No. 3, 2004, pp. 313-335. http://dx.doi.org/10.1080/03052150310001639911

[22] W. Hu, G. Y. Li and Z. H. Zhong, "Optimization of Sheet Metal Forming Processes by Adaptive Response Surface Based on Intelligent Sampling Method," Journal of Materials Processing Technology, Vol. 197, No. 1-3, 2008, pp. 77-88. http://dx.doi.org/10.1016/j.jmatprotec.2007.06.018

[23] R. A. Fisher, "Statistical Methods for Research Workers," Oliver \& Boyd, Edinburgh, 1925. 